\title{
Artelogie
}

Recherche sur les arts, le patrimoine et la littérature de l'Amérique latine

17| 2021

Transformaciones en Cuba contemporánea: cultura y sociedad

\section{Krudxs Cubensi: cuerpo y performance para derribar fronteras}

\section{Mabel Cuesta}

\section{OpenEdition}

Journals

Edición electrónica

URL: https://journals.openedition.org/artelogie/9990

DOI: 10.4000/artelogie.9990

ISSN: 2115-6395

Editor

Association ESCAL

Referencia electrónica

Mabel Cuesta, «Krudxs Cubensi: cuerpo y performance para derribar fronteras», Artelogie [En línea],

17 | 2021, Publicado el 27 septiembre 2021, consultado el 15 septiembre 2022. URL: http://

journals.openedition.org/artelogie/9990 ; DOI: https://doi.org/10.4000/artelogie.9990

Este documento fue generado automáticamente el 15 septiembre 2022.

All rights reserved 


\title{
Krudxs Cubensi: cuerpo y performance para derribar fronteras
}

\author{
Mabel Cuesta
}

"Devenir trans, como devenir- independiente, significa que de la nación como del género, hay que empezar por dimitir. Renunciar a la anatomía como destino y a la historia como prescriptora de contenidos doctrinales. Renunciar a la anatomía, a la sangre y al suelo como ley. Ni la identidad nacional ni la identidad de género pueden ser origen o fin de un proceso político. (...). Como el género, la nación no existe fuera de

las prácticas colectivas que la imaginan y la construyen. La batalla, por tanto, comienza con la desidentificación, con la desobediencia, y no con

la identidad. Rayando el mapa, borrando el nombre, para proponer otros mapas, otros nombres que evidencien su condición de ficción

pactada"

(Preciado 2019: 138)

En su artículo de 2007 “"Growing the Size of the Black Woman': Feminist Activism in Havana Hip Hop", Ronni Armstead establece con claridad cómo el “(..) hip hop has emerged on the island as a powerful form of political expression: a kind of "theater of the oppressed' (...)" (2007: 106). Una vez convergido que ese "teatro de los oprimidos" sería la más radical de las armas con que podría un/a artista desestabilizar a un 
régimen (cualquier régimen); importa asimismo establecer el argumento central de este ensayo. Dicho argumento asume la producción musical del CD Poderosxs en el año 2014 de les "Krudxs Cubensi" y sus respectivos audiovisuales "Mi cuerpo es mío" (2014) y "En el solar" (2016) como cúmulo de estrategias políticas con las que desdibujan un posible trazo entre elles, sus cuerpos y cualquier posicionalidad al interior del relato nacional/insular que pretenda ser entendida como unívoca o estable ${ }^{1}$.

2 Aunque lo anterior aparente ser una contradicción, de cara a lo que nos propone Armstead en su importante ensayo, invito mejor a asumirlo como parte de la narrativa evolutiva de este dúo que desde su fundación (como trío) en 1999 hasta la fecha ha pasado por certeros procesos de reinvención física y epistemológica.

\section{Algo de historia}

3 Un brevísimo recorrido por sus primeros años de colaboración nos informa que Odaymara Cuesta, Olivia Prendes y Odalys Cuesta (a.ka. Wanda Kruda) graban su primer álbum: Cubensi Hip Hop en el año 2003, en La Habana. Para el 2004 Wanda Kruda deja la agrupación lo cual deriva en que Odaymar y Olivia se establezcan, hasta la fecha, como dúo. Tanto en el mencionado disco del 2003, como en los que le aparecen sucesivamente con los títulos Kandela (2005); Resistiendo (2007); Krudas Compilación (2009) y Levántate (2012) sus trabajos musicales, giras internacionales y clases magistrales son promocionados con el nombre de Krudas Cubensi. Otro es, sin embargo, el escenario nominativo que nos presentan a partir del 2014 cuando graban y publican Poderosxs, Highly Addictive (2016) y LNL (2019) ${ }^{2}$. Esas tres últimas producciones, así como los videos ya anunciados y que discutiré como parte central de este trabajo, son divulgadas con el nombre de Krudxs Cubensi, declarando una posición ciertamente política de cara a la fluidez expresa de sus géneros. Asimismo, sus nombres cambian de Olivia a Oliver u Olivix y de Odaymara a Odaymar.

4 Otra fecha importante es la del año 2006 cuando se establecen en la ciudad de Austin, Texas. Desplazamiento ese que no constituye una ruptura radical con La Habana a la usanza de ciertas narrativas cubanas (ahora casi demodés) en torno a la isla y sus diásporas. Sin embargo, hay en lo anterior cierta excepcionalidad porque esa decisión de migrar es anterior a las graduales y generosas políticas que Barack Obama comienza a poner en práctica hacia Cuba desde el 2009 -cristalizando todas en el intento de normalización de relaciones diplomáticas (2014) y en los subsiguientes viajes comerciales y no regulados para cubanos desde USA (2016).

De igual manera, la relocalización de Krudxs Cubensi en Austin antecede a dos de las más celebradas medidas revisionistas de Raúl Castro: la no perdida de propiedades y derechos ciudadanos si no se excede un período mayor de veinticuatro meses en el extranjero y la eliminación en 2013 de la "tarjeta blanca" o "permiso de salida" impuesto también a nacionales cubanos ${ }^{3}$. 


\section{EL CUERPO LÉSBICO Y TRANSEXUANACIONAL, EL CENESEX ${ }^{4}$ CASTRONORMADO Y EL IMPACTO DE LAS NUEVAS TECNOLOgÍAS COMUNICATIVAS}

6 Antes de pasar a discutir el trabajo de Krudxs Cubensi, me permito una digresión en donde creo importante hacer un zoom de cámara al actual panorama de la nación lésbica cubana (ahora sí, la radicada en la isla) y al cómo las nuevas tecnologías de comunicación la han impactado.

7 El investigador norteamericano Ted Henken, en su artículo "Cuba's Digital Millennials: Independent Digital Media and Civil Society on the Island of the Disconnected", analiza el modo en que la sociedad civil se ha estado reconfigurando aceleradamente a partir de su entrada a las redes y cómo, a su vez, ello ha generado nuevas estrategias de pensamiento, comunicación y distribución digitales que han facilitado el debate de asuntos importantes y largamente silentes entre los ciudadanos. Para defender esta idea, presenta algunos datos relacionados con el pasado reciente y las expectativas de futuro vinculadas a dicha conectividad:

These developments began with an increase in the number and diversity

of Cuba's independent bloggers starting in 2004, followed by the

subsequent growth of collective projects of citizen journalism since

2008. These phenomena have been fueled by the opening of Cuba's

first public-access Internet cafés in June 2013, the possibility of accessing

e-mail via cell phone for the first time in 2014, the establishment

of 35 public Wi-Fi hotspots across the island in the summer of 2015,

and the simultaneous spread across the island of "el paquete" (the

packet), an informal digital data distribution system (Del Valle 2013).

The continued expansion of the Wi-Fi hotspot plan, which reached

200 hotspots in September 2016, and the launch by ETECSA (the state

telecom monopoly) of a pilot program to allow home Internet access

for the first time to 2,000 customers in Old Havana in late-2016, along

with its plans to offer Internet access via cellphone to paying customers

for the first time in 2017, are bound to facilitate the growth and

social impact of Cuba's independent media (Rodríguez Martinto 2016).

(Henken 430-431)

Olvidando por un momento los sustratos de trauma que aún aparecen en la sociedad civil cubana cuando se trata de discutir tanto la pertinencia de un estado de derecho para los sujetos lgbtiq como sus rizomas; parece igualmente sintomático que las lesbianas como grupo doblemente marginado, comiencen a atisbar ciertos hilos de esperanza a través de los intersticios que se abren para ellas en las redes sociales y otras formas de conectividad. El paquete semanal al que refiere Henken ha permitido, por ejemplo, que puedan disfrutar de series norteamericanas o europeas (The $L$ Word, Vis a Vis y similares) en donde tanto los personajes como sus historias son eminentemente lesbianas.

Al plantear lo anterior no estoy suprimiendo estas mismas posibilidades y esperanzas para el total de la comunidad lgbtiq; pero es importante recordar que las lesbianas han sido víctimas no solo de marginalidad, silencio y falta de representatividad mediática en tanto mujeres sino también en tanto homosexuales. A nivel global, tanto las mujeres homosexuales, como las bisexuales y las trans, han sufrido de largas exclusiones dentro de los movimientos feministas y lgbtiq; dominando en el primero las figuras de mujeres burguesas heterosexuales y en el segundo, los hombres gays. Entre las más violentas 
exclusiones sufridas por este grupo se encuentra la de no ser representadas en campañas contra la violencia de género. Al respecto abunda la investigadora y activista cubana Mercedes García Hernández:

10 La violencia que sufren mujeres homosexuales, bisexuales y trans está totalmente invisibilizada en las campañas dirigidas a eliminar la violencia contra la mujer, pensadas desde la heteronormatividad hacia la mujer de pareja heterosexual, que siempre es violentada por un hombre: su padre, el marido, un amigo, etc. (Gordillo Piña $2016 \mathrm{web})$

11 Me interesa entonces interconectar la obra de les Krudxs Cubensi -en tanto se identificaron como lesbianas hasta cerca de 2014 y en la actualidad como sujetxs no binarios- con los sedimentos productivos de dicho trauma. Y establecer también el cómo desde una mirada que tiene su génesis en lo local es posible emprender narrativas disidentes que devienen de naturaleza global. A la vez, propongo que para la comunidad lésbica y trans cubana va siendo pertinente tener acceso a las posibilidades de autorepresentación que facilitan las plataformas digitales diseñadas para la interacción social. Es en este sentido que el trabajo de les Krudxs ha implementado una proyección internacional de doble vía. Por un sendero va el hecho de que lesbianas y trans cubanxs puedan desarrollar una relación de pertenencia y diálogo con los azotes globales que atacan a sus comunidades y por el otro el que aparezcan proyectados en los videos de la pareja sus propios deseos y expectativas desde narrativas visuales que incluyan barrios y zonas rurales cubanas.

12 Debemos también recordar que, a día de hoy, las estadísticas sobre la violencia ejercida en contra de la comunidad lgbtiq -manifiesta en la discriminación laboral, el control sobre las cirugías de reasignación de sexo o el racismo- siguen siendo "secreto de estado". Los investigadores cubanos y extranjeros que hemos asumido la tarea de examinar tales datos nos hemos encontrado con magnas prohibiciones.

13 Atendamos entonces a lo que ha sucedido desde que en el 2006 Fidel Castro pasara el liderazgo como primer secretario del PCC y presidente del consejo de estado y de ministros a su hermano Raúl y éste a su vez intentara -apoyado en Mariela Castrohacer una suerte de saneamiento de imagen en cuanto al modo en que lidia el gobierno con la comunidad lgbtiq en la isla. Hecha esa atenta revisión se desvela fácilmente que nada verdaderamente revolucionario le ha sucedido a este colectivo en términos de derechos. Hasta el día de hoy, el matrimonio igualitario es sólo una promesa que sufrió una dura estocada al quedar fuera de la nueva constitución aprobada en el $2019^{5}$. Asimismo, no hay derechos parentales, ni de reproducción, ni poder expreso a través de representación gubernamental para parejas del mismo sexo o sujetos lgbtiq.

14 A la vez y problematizando más este asunto, no escapa a casi nadie la gran ironía que constituye el hecho de que la comunidad lgbtiq cubana sea "visible" nacional e internacionalmente a través de una representante del mismo poder heteronormativo y censor que por más de cuarenta años la fustigó. Es decir, el sempiterno poder de la familia Castro, representado ahora por una mujer de la próxima generación: la sobrina/ hija Mariela Castro.

15 Si sólo indagamos con cierta seriedad, descubrimos que perviven aún ejercicios de control policial, conocidos como "redadas" perpetradas con regularidad contra travestis y trans en sus puntos de encuentro en La Habana. Siendo así, no resulta difícil concluir que ese mismo poder de representación y legitimidad que Mariela Castro propone desde el CENESEX, está entregando a los medios de difusión un discurso pre- 
escrito y pre-aprobado por la nomenclatura poderosa que en los sesentas condenaba a los individuos de clara preferencia homosexual a los campos de concentración conocidos como UMAP'.

Tomar el pulso de la comunidad lgbtiq en la isla entrañaría el gesto, con frecuencia olvidado, de escuchar las voces de quienes no están asociados al CENESEX. Además, habría que entender que ese "Centro" puja por una normalización y control de todos aquellos cuerpos que no respondan al modelo hegemónico y largamente desfasado que la tradición estalinista ha propuesto e impuesto a la ciudadanía cubana. Como ejemplo, hay que revisar los sucesos del 15 de mayo de 2019 cuando luego del frustrado intento de hacer constitucional el matrimonio igualitario, el CENESEX -sospechosa y arbitrariamente- decidió cancelar su habitual (desde el 2008) marcha en celebración de “jornadas contra la homofobia". En respuesta, ciertos actores de la sociedad civil decidieron marchar libremente por el Paseo del Prado habanero. Dicha marcha terminó siendo reprimida por la policía ya que no contaba con los permisos pertinentes. Léase aquí: los del CENESEX?.

La investigadora Frances Negrón Muntaner, ha venido anotando con acuciosidad algunos de los más significativos modus operandi del CENESEX y los ha resumido en su fundamental ensayo “'Mariconerías de estado': Mariela Castro, la comunidad LGBTQ y la política cubana”:

Si bien dentro y fuera de Cuba, la labor de Castro Espín se interpreta como una defensa radical de la comunidad LGTBQ contra el prejuicio, una lectura cuidadosa apunta a que su discurso está marcado por lo que podríamos llamar un fuerte "maternalismo" autoritario. Por ejemplo, en sus intervenciones en los medios de prensa y televisión, Castro Espín imagina las necesidades de los travestis en términos muy similares a los niños y adolescentes. El asunto no es, por ejemplo, que los travestis socialicen libremente y determinen como quieren ser (o no) representados políticamente. Más bien, según señala Castro espín en un video de CENESEX titulado Sexualidad, un derecho a la vida (2005), a los travestis hay que "atenderlos", "escucharlos" y, sobre todo, "comprenderlos". (Negrón Muntaner 115)

18 Al margen de lo que plantea Negrón Muntaner, resulta difícil aceptar como legítimo el discurso que Castro Espín ha ido construyendo a través de declaraciones y entrevistas sobre democracia y diversidad. Cuando se apresta a declarar una igualdad de deberes y derechos para todos los sujetos que viven en la isla -con independencia de sus condiciones de raza, clase $u$ orientación sexual- en realidad está enterrando todo aquello que pueda resultar ajeno a su propia idea de nación: una nación castronormalizada tanto para la ciudadanía queer como para la no queer ${ }^{8}$.

\section{Algunos krudxs videos para el fin de las fronteras}

19 Establecida pues, grosso modo, la historia del dúo y el contexto socio histórico en el que sobrevive la comunidad lgbtiq dentro de la antilla mayor, me gustaría ilustrar el cómo si por un lado es efectivamente cierto que en el 2003 mientras Sujatha Fernandes discutía el status de la sociedad afrodescendiente en la isla, asegurando que " (...) it is not surprising that the female body would again become a site of contestation (...) (Fernandes 2003: 592); por el otro, hay también en los intereses de les krudxs una narrativa que reconfigura sus temas y denuncias con un desplazamiento que de manera circular parte desde lo nacional hacia lo global y luego regresa. Y que todo lo anterior 
sucede en consonancia con las experiencias transicionales que van auto-operando sobre sus propios cuerpos.

Si en algún momento durante su primera década de trabajo (2003-2013) esos cuerpos pueden leerse (no estrictamente; pero mayoritariamente) como metáforas de lo nacional y transnacional cubano ya que arremeten contra un medio ambiente civil y político que en principio no las protege legalmente declarándolas, de facto, "personas non gratas"; más adelante, tal y como lo demuestran los videos que aquí analizaré, comienzan a subvertir dicho mensaje de "no deseabilidad", articulando un muy descarnado llamado de atención sobre los azotes que nos amenazan si seguimos entendiendo los cuerpos como estancos que acumulen nociones fijas sobre la raza, el género o la patria.

21 En principio y como recién señalaba, les Krudxs Cubensi solían presentarse más fácilmente legibles si nos acercábamos a elles desde un ángulo que les contuviera como una de las más disidentes representaciones de "la revolución" y sus modelos de ciudadanía asignados a la mujer. Pero en su tránsito físico y epistemológico ensayan una desterritorialización para sus cuerpos que desemboca en un constante desafío que dinamita y corrompe tanto a la ensayada castronormatividad propuesta desde el CENESEX como al patriarcado ${ }^{10}$. Institución ésta última que es presentada en su obra como extremadamente tóxica en la medida en que contamina, controla y extorsiona la mera existencia de todo cuerpo alterno.

22 A lo hasta aquí descrito, insisto, debe sumarse que su mensaje sí se vale de referentes locales -especialmente a nivel visual- pero ese mismo mensaje es recolocado en una dimensión que encuentra ecos en preocupaciones de orden global. La noción de lo glocal, como impulso diluyente de fronteras posiciona tanto a les Krudxs como a sus colaboradores y seguidores, en una dirección que hace posible percibirles como gestores de una visión que piense a Cuba fuera de sus tradicionales estancos de excepcionalidad. La misma excepcionalidad que desde la tardía descolonización (1898-1902) ha acompañado a sus narrativas nacionales y transnacionales.

Para ilustrar lo anterior discutiré, como botón de muestra, fragmentos de dos de sus clips musicales producidos a partir del 2014. Dichos videos son los titulados "Mi cuerpo es mío" (2014) y "En el solar" (2016) ya que en ellos, arguyo, es en donde se pueden leer con mayor fruición las prácticas de insubordinación, inestabilidad genérica y glolocalidad que considero esenciales para la totalidad de la obra de Krudxs Cubensi.

El tema "Mi cuerpo es mío" (2014) abre con una pregunta que de modo inmediato encuentra respuesta al tornarse declaración de fe: "Whose bodies?/ Our bodies/ Whose rights?/ Our rights/ ¿Cuerpos de quiénes?/De nosotres/ ¿Derechos de quiénes?/ De nosotres/ ¿Decisiones de quiénes?/ De nosotres/ Krudas Cubensi/ one more time/ representing women and queer people choices" (Krudas Cubensi 2014 0:09-0:32). Varias intersecciones hay aquí que parecen importantes a destacar.

En primer lugar, ese fluido "code switching" que, si bien no es una novedad para los artistas US Latinx; sí lo es para creadores que recibieron toda su educación formal en la monolingüe isla de Cuba. "Code switching" que además encuentra en sus textos inmediata convivencia con el aún pujante y controversial "lenguaje inclusivo". Ese "nosotres" que resuena en el título de la totalidad del álbum Poderosxs que es en donde aparece el tema ahora comentado. 

"queer" a quienes pretenden representar sin que esto suponga una localización geográfica, étnica o racial específicas. Sin embargo, más adelante, al interior del mismo tema, sí harán un aterrizaje en parajes concretos al identificarse como "Afrolatina, americana y caribeña/ Orgullo de mi gente y de mi cuerpo dueña" (Krudas Cubensi 2014 $1: 47-2: 08)$. aseveraba en relación con la intencionalidad del dúo de desplazar (para amplificar) su mensaje desde un centro local (La Habana o Austin) hacia un espacio en donde sea el patriarcado como sistema cultural tóxico y transnacional quien quede emplazado "Saquen sus rosarios de nuestros ovarios/saquen sus doctrinas de nuestras vaginas" (Krudxs Cubensi 2014 0:34-0:48). Vemos así, cómo aparece la pareja reclamando absoluta autoridad para sus cuerpos y enfatizando que ni la revolución iniciada en 1959 por el aún vigente gobierno cubano, ni las propuestas imaginarias y pragmáticas (legislativas) de la mayoría de los estados contemporáneos tienen significación o contenido real para las mujeres en general y las mujeres queer en particular, siendo que no les representa.

Establezco este video -junto al que de inmediato pasaré a comentar "En el solar" (2016)- como parteaguas al interior de la totalidad de la obra de Krudxs Cubensi en la medida en que (a nivel audiovisual) son las primeras producciones en donde su mensaje viaja desde lo global ("Mi cuerpo es mío") hacia lo local ("En el solar"); afianzándose allí para, una vez conseguidas sus denuncias, volver a saltar hacia lo global.

Si bien ambos temas aparecen en el disco Poderosxs de 2014, hay entre la publicación de los videos, dos años de diferencia. Años que quizás deberíamos tener en cuenta en la medida en que son justos los que coinciden con el inicio del deshielo de las relaciones entre Cuba y Estados Unidos; lo cual quizá facilita que la grabación del segundo ocurra completamente en escenarios habaneros.

30 Pasando entonces a discutir con mayor exhaustividad "En el solar" (2016), lo primero que habría que señalar es el cómo les artistes, sin ambages, desafían la idea de equidad social y el no sometimiento de clases en Cuba. Lo hacen tomando como hilo articulador tormentosas imágenes de pobreza en la ciudad de La Habana. Hay asimismo que anotar que la pobreza ha sido desde la propia génesis del trío (luego dúo) eje central en sus líneas de pensamiento; cuidando siempre que aparezca en directa conversación interseccional con la raza negra, siempre subordinada en la isla.

31 Regresando al fundamental artículo de Armstead, el cual se sostiene sobre largos fragmentos de entrevistas, Odaymara Cuesta ya expresaba en el 2007:

More than being Cuban, I am a poor Cuban. ¿Entiendes? A more humble Cuban.

Because they say that in Cuba there are not classes, that everybody is working

class. But in Cuba there has been achieved a differentiation, let's say, of certain social scales; there are people [here] who have a car and a house. There are people here who have neither car nor house. ¿Entiendes lo que estoy diciendo? Do you understand what I'm saying? And I am one of those people who have neither car nor house. Nothing. So I wake up in the morning wondering if at night I'm going to sleep in the same [bed] where I'm living now. So I tell you that [I identify with the] poor, women, artists, Cuban, Black, hip hop. (Armstead 2007: 107)

Como mencionaba antes, me interesa discutir en conjunción estos dos materiales de les Krudxs porque si en "Mi cuerpo es mío" se confronta a las históricas instituciones 
occidentales (iglesia, estado y matrimonio): “(...) saquen sus rosarios de nuestros ovarios/saquen sus doctrinas de nuestras vaginas/ ni amo, ni estado, ni partido, ni marido" (Krudxs Cubensi 2014 0:48-1:02); ya en "El solar" lo confrontado es específicamente el gobierno cubano y la falta de recursos en las que viven las comunidades de afrodescendientes.

En esta segunda producción, antes de que aparezcan en la pantalla las imágenes y música que conforman la canción, se nos muestra una dedicatoria en dos pantallas consecutivas; pero independientes en donde podemos leer "Habana, a ti te quiero/De verdad" (Krudxs Cubensi 2016 0:18-0:24) ${ }^{11}$. Esa dedicatoria nos orienta hacia dos planos de interpretación contiguos, mas no idénticos. El primero descansa sobre la cláusula circunstancial "De verdad". El que ésta aparezca en una pantalla independiente de la línea que la antecede, potencia la idea de que el video y la canción son para una ciudad a la que quieren auténticamente (sin pose, sin extorsiones, de manera horizontal). El segundo plano que ya contendría la frase entera, se asegura que no sea posible alejar el mensaje que estamos a punto de escuchar y ver de su referente más inmediato. Para enfatizar aún más esa imposibilidad, la dedicatoria es sucedida por una serie de tomas rápidas, fragmentadas y yuxtapuestas tanto de sitios icónicos al discurso de la revolución (la bandera en el malecón, las consignas de "venceremos", la Plaza de la Revolución, etc.) como por sitios históricos que identifican la ciudad (el Morro, el Malecón, el Prado, la ex embajada de Estados Unidos, etc.); mezclados todos los anteriores con los que finalmente constituirán el centro de la narrativa visual del video: las calles sucias de barrios no expuestos a los turistas, vertederos de basura, grafitis, pescadores, barrenderos, bicitaxeros y autobuses.

Esos primeros segundos de la historia, podrían ser leídos, como otra declaración de fe; pero también de fidelidad. Tras su inicial voluntad de exponer todo lo que La Habana es, los espacios centrales para la escenografía pasan a ser el solar, los barrios eminentemente poblados por afrodescendientes y los basureros. Con ello, se articula un muy claro gesto político en donde quedan anuladas y contestadas las enormes capitalizaciones que hacen de una Habana para turistas, glamurosa y resorte de nostalgias, artistas contemporáneos como Descemer Bueno o Kelvis Ochoa ${ }^{12}$.

Resulta interesante comprobar, que ya desde el 2008, en otro ensayo titulado esta vez "Las Krudas, Spatial Practice, and the Performance of Diaspora" ya Armstead decodificaba de manera perfecta esta estrategia de les raperes:

Las Krudas are especially helping to disrupt the classificatory eye's orientalist gaze -which visually and aurally disciplines space through the distribution of bodies and voices-through their public performances. In the tourist zones the classificatory eye looks upon a sanitized space, producing, in concert with the ear, ordered visual and aural landscapes evocative of the "authentic" Cuba. I suggest that sound can make visible spatial practice. Las Krudas perform music and theater -aimed at disrupting the definition of who is authentically Cuban-in the heart of the tourist zone (Armstead 2008: 130).

Una vez que arrancan música y texto, la letra discurre desde la descripción de la vida social de un solar habanero “(...) con sus colores, con su habitar, con su bullicio, con su lavar, con su chisme y su cooperar, ya la maraca empezó a sonar (...)" (Krudxs Cubensi 2016 1:14-1:20) hasta la real acusación de los estados de pobreza a la que están sometidos sus moradores “(...) qué miseria, qué alegría, abierto los basureros, derrumbe de vertederos, dondequiera los mosqueros, room for rent, bicicleteros, en cada grieta una 
flor, en cada mierda un color, en cada casa calor, se quemó el ventilador (...)" (Krudxs Cubensi 2016 1:33-1:44).

La enumeración anterior es desarrollada aún mejor a lo largo de los cuatro minutos por los que se extiende la canción conteniendo semas que nos reportan insalubridad, derrumbes de edificios, alcoholismo, colas, falta de transportación pública, ventas ilegales, represión policial, escaso acceso a la internet y peticiones a las deidades africanas quienes serían una suerte de refugio -acaso enajenante- ante la incertidumbre del presente ${ }^{13}$. más empobrecido espacio urbano habanero, prevalece una proyección amorosa sobre y por la ciudad que es también leitmotiv. Las enunciaciones sobre lo roto, desvencijado, precario e insalubre, se cosen a sí mismas con un hilo delicadísimo, uno que repite Habana es mi ciudad/ Habana yo a ti te quiero/Habana... el mismo con el que cierran la canción y que es ya no una declaración de fe -como en "Mi cuerpo es mío" o como en la dedicatoria de este misma producción- sino una de fidelidad.

Vale notar que las palabras "fe" y "fidelidad" comparten la raíz latina "fides" y parecería ese un detalle nimio; pero lo propongo como significante tanto al destacar convergencias entre estos dos temas, así como al ensayar una poética recurrente en los textos de Krudxs Cubensi. La fe que proyectan sobre sus cuerpos, la autonomía y demandas de libertad que piden para ellos, apela a un discurso de pertinencia global, siendo como son cuerpos desplazados a los que no interesa (en apariencia) mostrarse anclados a un espacio específico. Sin embargo, esa misma fe se trastoca y fusiona con la fidelidad si el espacio en donde deben ser aterrizadas sus miradas e identidades, es La Habana: “(...) en el solar yo estoy, yo no me he ido” (Krudxs Cubensi 2016 1:28-1:30).

El acto de feminizar con su mirada a la ciudad les permite también presentarla como a otro cuerpo; acaso el más deseado de entre todos los de mujer que conocen; acaso el único a quien pueden serles completamente fiel; procurándose así "agencia sobre" y "posesión de" la amante Habana. Agencia y posesión que, otra vez, no se consigue mirando desde arriba sino a través de planos de cámara centrales y bajos. Las únicas tomas de planos aéreos que hay en el video son aquellas que como recién señalaba aparecen al inicio con la intención de mostrar los sitios icónicos de la ciudad. Esa Habana que sí sale en las postales; pero que no forma parte del cosmo de les Krudxs.

Dos elementos añadidos a los hasta aquí expuestos facilitan esa lectura encaminada hacia el ars amatoria. El primero es la portada misma del CD Poderosxs que es también la primera imagen del video. En esos soportes visuales les miembres del dúo aparecen sosteniendo y apretando sus genitales en claro gesto que evoca a otro muy familiar -al menos en los países y zonas del Caribe hispano. Gesto que de ordinario es asociado a los hombres cuando hacen alarde de su potencia y virilidad. El segundo es el saludo que se regalan en la escena que antecede al comienzo de la música. Odaymar entra al solar, da los buenos días a una vecina que limpia el pasillo comunal y luego toca a una puerta que abre Oliver. El saludo tradicional de las mujeres en Cuba sería el de un beso y un abrazo si ha transcurrido largo tiempo sin verse. En este caso, dicho beso es sustituido por un saludo de manos en alto, al que sucede un apretón de éstas y culmina en un abrazo que en realidad es choque de hombros. Una vez más, la performatividad de sus fluidos géneros se encamina hacia prácticas usadas con mayor frecuencia por hombres que por mujeres. 
42 Ese proceso de virilización -al que elles de ordinario desestabilizan con estrategias que van del uso ya comentado de la " $x$ " y la "e" a las arbitrarias apariciones de la "a" en pronombres como "mía" cuando acuden a él para designarse mutuamente- podría en el caso de "En el solar" tener como objetivo último el enmascararse tras esa masculinidad históricamente empoderada, para desde allí, una vez apropiadas máscara y poder, ejecutar su bilateral plan de acciones: el de la denuncia social y el de la muestra de amor incondicional. Una representación que se articularía sobre la más noble de las razones: si a la amada la están maltratando los hombres, otros que usen sus mismos gestos y el circunstancial poder de la voz, vendrán a denunciarlo.

A La Habana le confieren, además, cierto aire de humanizada espiritualidad, de diosa a quien se invoca y cuida; gesto habitual ante las pérdidas y la desesperanza: "Habana centra el conjuro, yo te quiero te lo juro, Habana yo a ti te quiero, Habana. Ofrezco mis respetos a tu sublime presencia que ha sobrepasado toditas las carencias. Bendición pa'tu pasión, aprendizaje y paciencia, de anteriores, actuales y futuras existencias" (Krudxs Cubensi 2016 3:45-4:04).

44 Finalmente, la coda del audiovisual -la cual es proyectada en blanco y negro y se extiende del minuto 5:13 al 6:36- es la que una vez más nos propone el salto desde la preocupación local (todo lo recién descrito y analizado en torno a La Habana) hacia una zona mucho más amplia y de resonancia global. En dicha zona, aún cuando son sus propios cuerpos en transición los usados como pretexto y un área periférica y altamente deprimida de la ciudad es su paisaje acompañante; les Krudxs Cubensi vuelven a proponernos una reflexión sobre sus identidades genéricas y el cómo expresarlas a nivel nominativo. Una vez terminada la parte musical del video, aparecen saliendo del solar y desde allí, en la próxima toma, en el área muy pobre recién comentada. Desde que, de espaldas a la cámara, salen del solar, se enfrascan en este diálogo: “(...) ¿te explico? Sí, te explico. Les que, lus que, las que, les que, lis que, lus que, los que, viejo, los que, somos los que (...)" (Krudxs Cubensi 2016 5:13-5:27).

Destaco este fragmento -así como otras breves intervenciones que aparecen en el minuto que sigue en donde se dedican a una improvisación rapera y a capela- como uno que catapulta otro lanzamiento de su sistema epistémico hacia lo global. Y así lo propongo porque el debate sobre el lenguaje inclusivo, en Cuba, no ha comenzado todavía. Y ya es 2020. Ni los minúsculos grupos activistas (controlados o no por el CENESEX) ni las instituciones tipo "Academia Cubana de la Lengua", han hecho pronunciamientos al respecto. La prensa y los medios de comunicación oficiales o independientes, tampoco se han hecho eco de ello.

De modo que tanto ese insertar la propuesta sobre el cómo deben ser (auto)reconocides y (auto)nominades les sujetes genéricamente inconformes; así como la elección del paisaje, el blanco y negro y la improvisación, vienen todos a servir a la idea de mayor impacto glocal en el video: la del cimarronaje.

Krudxs Cubensi, autodeclaradas guerreras y cimarronas, no se atienen a un guion predeterminado para elles (como el del CENESEX); no aceptan narrativas coloridas y nostálgicas en torno a una Habana que se derrumba ante sus ojos, bajo sus pies (a pesar de que ello podría atraerles para sí a un mayor y más internacional público, ávido de consumir la ciudad desde ese lugar); no olvidan el barrio, el solar y las comunidades sufrientes que en ellos habitan; no se conforman con un solo nombre, un solo género, una sola proyección sobre sus identidades sexuales porque de hacerlo traicionarían la 
misión mayor: la de denunciar al patriarcado, la iglesia y los gobiernos que meten rosarios en ovarios y doctrinas en vaginas.

La voluntad denunciadora que hay en su trabajo no necesita tener como telón de fondo a un escenario específico ("Mi cuerpo es mío") y con ello producir un sistema de referencias que arremeta contra azotes de orden global. Sin embargo, pueden también desde la ciudad en la que crecieron y a la que regresan con harta regularidad- proponer una conversación que convoque a otras comunidades cimarronas y no binarias que a lo ancho del globo sobreviven con similares precariedades.

Prueba de ello se esconde en el paratexto que constituye que una de las productoras del video "En el solar" no sea otra que la Astraea National Lesbian Foundation for Justice, radicada en Nueva York para luchar por los derechos de lesbianas, trans y sujetxs intersexuales desde 1977. El propio slogan con el que esta fundación se promueve nos habla de convergencias significativas para la misión de Krudxs Cubensi: Hyperlocal Impact. Global Reach ${ }^{14}$. Para ganar la beca que permitió la grabación y publicación de este tema y las narraciones que lo acompañan a modo de "intro" y "coda", Krudxs Cubensi supieron articular una propuesta que apelara no solo a la crisis socio-política cubana, sino a las demandas de comunidades que, a nivel global, sobreviven en condiciones de cimarronaje similares.

\section{Apuntes inconclusos}

Otras producciones posteriores a las aquí discutidas siguen hilvanando un tejido denso que sin dudas servirá para continuar armando la siempre reinventada manta de disidencias, emplazamientos, cimarronajes y confrontaciones conque Krudxs Cubensi nos arropa. Llamo la atención, y con ello la posibilidad de continuar esta conversación inicial, sobre la producción videasta que acompañan el tema "Todavía" (2017) rodada en el Bronx, N.Y., la cual forma parte del disco Highly Addictive (2016) el cual fue grabado en La Habana. Y también sobre el último de sus videos hasta la fecha "Sinca Misa" (2019), rodado entre La Habana y zonas rurales no especificadas. El tema "Sinca Misa" aparece en su último disco LNL (2019). En la portada de dicho CD, les artistes aparecen fotografiadas de espaldas, mirando en la distancia, cómo flota el globo terráqueo. Por otra parte, en el video publicado en YouTube el 5 de mayo del 2019, aparece la siguiente nota publicada por elles:

Thanks so much every person in this video, thanks life! Muchas gracias a cada persona en este video, gracias vida. Nuestra lucha por derechos continúa. Feministas. Our rights. Free the nipple is just a symbol, lets fight the unjustice. Topless is our right. Sincamisa es nuestro derecho y eso es solo un símbolo entre las tantas luchas que tenemos que librar las personas no conformes con los estereotipos de genero y el injusto "Cistema" nuestros cuerpos son nuestros, nuestros derechos serán exigidos de todas las maneras necesarias, by any means necesary (Sic) ${ }^{15}$. (Krudxs Cubensi 2019)

51 Resulta, en fin, plausible argüir que la revolución "krudx" y "cubensi" es también el acto de hablar desde las intersecciones ya que los suyos son cuerpos atravesados por varias de ellas. Este par de artistes son negres, pobres, queers e inmigrantes en constantes viajes de ida y vuelta. Todo lo anterior les concedería cierta sui generis y no reclamada autoridad al tener la posibilidad de comparar sociedades, formas de explotación y consumo, ideologías y representaciones imaginarias del poder. Dicha posibilidad queda traducida en sus textos y producciones audiovisuales en forma de 
denuncia que ataca tanto a las formas de subyugación sicosociales como a las instrumentadas por gobiernos y partidos específicos. Desafían a las instituciones porque no les interesa cumplir el mandato para el que fueron asignadas. Nada ni nadie las normaliza. Su tribu late en un solar de La Habana; pero ese latido sirve para convocar a sus pares en marginalidad: cimarrones rebeldes ante la dominante injusticia que sofoca en/al planeta.

\section{BIBLIOGRAFÍA}

Armstead, Ronni (2007), “'Growing the Size of the Black Woman': Feminist Activism in Havana Hip Hop" en NWSA Journal, Vol. 19, No.1: 106-117.

Armstead, Ronni (2008), "Las Krudas, Spatial Practice, and the Performance of Diaspora” en Meridians: Feminism, Race, Transnationalism, Vol. 8, No. 1: 130-143.

Fernandes, Sujatha (2003), "Fear of a Black Nation: Local Rappers, Transnational Crossings, and State Power in Contemporary Cuba" en Anthropological Quarterly, No 76: 575-609.

Henken, Ted A. (2017), “Cuba's Digital Millennials: Independent Digital Media and Civil Society on the Island of the Disconnected" en Social Research. An International Quaterly. The New School, Vol. 84, No.2: 429-456.

Gordillo Piña, Lirians (2016), "El silencio hacia las mujeres lesbianas y trans es violencia". (Entrevista a Mercedes García Hernández). SEMIac en Corresponsalía en Cuba del servicio de noticias de la mujer de Latinoamerica y el Caribe, http://www.redsemlac-cuba.net/diversidad-sexual/elsilencio-hacia-las-mujeres-lesbianas-y-trans-es-violencia.html

Kubensi, Krudas (2016), En el solar en YouTube, 26 de marzo, https://www.youtube.com/watch? v=DoLCwU6gQXY

Kubensi, Krudas (2014), Mi cuerpo es mío en YouTube, 21de junio, https://www.youtube.com/ watch?v=x-Pgwldfx8U

Kubensi, Krudas Sinca Misa (2019), en YouTube, 5 de mayo,

https://www.youtube.com/watch?v=1QTqHyWsH7Y

Kubensi, Krudas. Todavía (2017), en YouTube, 26 de mayo, https://www.youtube.com/watch? $\mathrm{v}=71186 \mathrm{rnwy} 2 \mathrm{k}$

Negrón Muntaner, Frances (2016), “'Mariconerías de estado': Mariela Castro, la comunidad LGBTQ y la política Cubana”, en Nuestro Caribe. Poder, Raza y Postnacionalismos desde los límites del mapa LGBTQ. Ed. Mabel Cuesta, Isla Negra, San Juan, Puerto Rico: 105-123

Martínez-San Miguel, Yolanda (2008), “Más allá de la homonormatividad: Intimidades alternativas en el Caribe hispano”, en Revista Iberoamericana, Vol. LXXIV, Núm. 225: 1039-1057.

Preciado, Paul B. (2019), Un apartamento en Urano. Crónicas del cruce, Kindle ed., Editorial Anagrama. 
Saunders, Tanya L. (2009), "La Lucha Mujerista: Krudas CUBENSI and Black Feminist Sexual Politics in Cuba", en Caribbean Review of Gender Studies, Mona, Jamaica, University of the West Indies: $167-185$.

Saunders, Tanya L. (2010), "Black Lesbians and Racial Identity in Contemporary Cuba”. En Black Women Gender and Families. Volume 4, Number 1 (Spring). Champaign Urbana, University of Illinois Press: 1-28.

Saunders, Tanya L. (2011), "Black Thoughts, Black Activism: Cuban Underground Hip-hop and Afro-Latino Countercultures of Modernity”. Latin American Perspectives, Issue 183, Vol. 39 No. 2: $42-60$.

\section{NOTAS}

1. El uso del pronombre personal "elles" se irá explicando a sí mismo en la medida en que se desarrolla este ensayo. Más allá de una declaración a favor o en contra del lenguaje inclusivo, me lo permito como un acto de respeto hacia les artistes Krudxs Cubensi quienes así se expresan y autodenominan en sus canciones: Oliver/Olivix Prendes (antes Olivia Prendes) y Odaymar Cuesta (antes Odaymara Cuesta). Ver web personal de les artistes: http://www.krudascubensi.com/

2. Todos y cada uno de los álbumes que han grabado Krudas/Krudxs Cubensi han sido producido de manera independiente por su compañía "Krudas Cubensi". En el caso de los últimos cuatro discos, así como el single Respirando están publicados y licenciados por Cdbaby y son vendidos en las plataformas digitales de música incluyendo Spotify y iTunes.

3. Menciono dichos paquetes de medidas porque con posterioridad a sus respectivas ejecuciones se puede observar un mayor fluido de artistas desde la isla hacia Estados Unidos. Viajes que muchas veces derivan en largas estancias y contrataciones laborales en USA sin que ello represente una migración definitiva. Por otra parte, desde los noventas y gracias a la política conocida como "intercambio cultural", muchos artistas han llegado a territorio estadounidense. Tal es el caso de les Krudes Cubensi quienes se instalan en Texas con anterioridad a las nuevas dinámicas establecidas por Barack Obama y Raúl Castro.

4. El Centro Nacional para la Educación Sexual (CENESEX) es una institución asociada al Ministerio de Salud Pública. Pido especial atención a la asociación entre una institución para la salud y el agrupamiento oficial de los sujetos lgbtiq en torno a ella. Mariela Castro es la directora de dicho centro y es además hija de Raúl Castro quien fuera desde el 2006 hasta el 2018 el primer secretario del partido comunista de Cuba y presidente del consejo de estado y de ministros.

5. La ley de matrimonio igualitario no consiguió colocarse en la letra de la nueva constitución aprobada el pasado 24 de febrero de 2019. En el artículo 68 del anteproyecto constitucional que se sometió a debate se preveía establecer que el matrimonio era una unión entre dos personas, sin precisar el género; pero frente el revuelo que causó esta modificación entre los sectores más conservadores de la sociedad (léase de diferentes iglesias protestantes, las autoridades finalmente optaron por una fórmula más imprecisa que no reconoce el matrimonio gay, aunque tampoco lo impide. La próxima etapa de este debate tendrá lugar en el parlamento cubano que 
tiene ahora un plazo de dos años para legislar sobre el matrimonio y someter la nueva ley a un nuevo referendo.

6. UMAP: Unidades Militares de Apoyo a la Producción. A ellas fueron condenados, para hacer trabajos forzados, cientos de homosexuales cubanos entre 1965 y 1968.

7. Más detalles de los sucesos del 15 de mayo son detallados en el artículo periodístico de Carlos Manuel Álvarez "Miedo, fiesta y represión: una pelea cubana contra el demonio", disponible en el siguiente enlace: https://elpais.com/internacional/ 2019/05/15/actualidad/1557934824_744776.html

8. Utilizo el neologismo "castronormalizada" como parte de la hipótesis colateral que aquí defiendo: la familia Castro continúa al poder ya que Raúl Castro se mantiene como primer secretario del Partido Comunista de Cuba (PCC) y dicho partido es el órgano rector de la nación; de modo que la figura del presidente Díaz Canel funciona sólo a nivel simbólico como una estrategia de ilusoria pluralidad. Dicha inmovilidad ideológica y de gobierno, facilita que las estrategias de normalización para un modelo único de ciudadanía que sesenta años atrás fueron instaladas desde las organizaciones de masas (FMC, CDR, MTT, etc.) puedan ahora ser desplazadas 'hacia' y recicladas 'desde' el CENESEX a través de una figura que no solo pertenece al clan familiar gobernante, sino que además detenta el control para establecer qué miembros de la comunidad lgbtiq son o no aceptables.

9. No existe una declaración oficial en donde Odaymar y Oliver hayan sido declarades "personas non gratas"; de hecho, más adelante argumentaré el cómo los videos aquí discutidos han sido producidos por elles en Cuba. Uso entonces esta denominación no desde su carga legal, sino desde su capacidad de tropo. Y así me lo permito porque su establecimiento en Estados Unidos en 2006 delata la inconformidad de vivir en la isla en donde la ausencia de derechos para sujetos lgbtiq sigue siendo un lugar común. Asunto que también debato a lo largo de esta pieza.

10.

11. Uso la barra simple para demarcar qué frase aparece en cada una de las dos pantallas mencionadas.

12. Menciono a estos compositores y cantantes solo por recurrir a dos de entre los muchos que han elegido estrategias visuales de nostalgia y romantización de La Habana para acompañar sus producciones video-musicales. Pero un motivo añadido es que tanto Kelvis Ochoa como Descemer Bueno, comparten la experiencia de haber vivido por largas temporadas fuera de Cuba (Kelvis) o entre La Habana y Miami (Descemer). Ténganse como referencia a mano la producción que los unió a ambos en ese intento de idealizar la ciudad: "Quédate" (2010), canción y respectivo video éste que han sido leídos de modo popular como una invitación a los regresos que ellos mismos total o parcialmente han protagonizado. Video disponible aquí: https://www.youtube.com/ watch?v=moLphBdYnZ4

13. Hago la aclaración sobre la duración en minutos de la canción porque ésta no se corresponde con la longitud temporal del video de seis minutos y cuarenta y cinco segundos. Los dos minutos y cuarenta cinco segundos restantes que no están acompañados de música, son empleados tanto en un prefacio (dedicatoria, imágenes de La Habana ya mencionadas y la entrada de Odaymar Cuesta al solar, saludando vecinos y buscando a su compañerx oliver) como a una coda que discutiré más adelante.

14. Para mayor información sobre la Astraea National Lesbian Foundation for Justice y su misión, consultar su página: https://www.astraeafoundation.org/

15. La nota aquí usada como cita, aparece debajo del video, en donde los usuarios del canal de YouTube, en este caso Krudxs Cubensi, publican créditos y en ocasiones las 
letras de las canciones. Disponible en este link: https://www.youtube.com/watch? $\mathrm{v}=1 \mathrm{QTqHyWsH7Y}$

\section{RESÚMENES}

En 1999 se funda en La Habana el trío de Hip Hop cubano conocido como "Krudas Cubensi". En 2006, emigran a Estados Unidos en donde han sido reconocidas como músicas, activistas, educadoras, perfomeras, compositoras y pioneras del afrolatin hip hop. Mi propuesta al estudiar su trayectoria es leerlas desde una materialización y exploración de varias agendas políticas que parten desde sus propios cuerpos con el fin de desestabilizar aquellos discursos hegemónicos que componen el aún dominante imaginario patriarcal, heteronormativo, blanco, delgado, depredador del reino animal y del medio ambiente. El grupo "Krudxs Cubensi" (quienes han cambiado la femenina $a$ de su nombre original por la neutral " $x$ ") a convertido sus cuerpos y su obra musical, en terreno de experimentación para que operen en y sobre ellos, aquellas luchas tanto contra al status quo de la política cubana y sus gobiernos que contra los macro-poderes que nos intentan controlar a nivel global.

Le trio cubain Hip Hop connu sous le nom de "Krudas Cubensi" a été fondé à La Havane en 1999. En 2006, ils émigrent aux États-Unis où ils sont reconnus dans le milieu du spectacle comme musiciens, activistes, éducateurs, interprètes, auteurs-compositeurs et pionniers du hip-hop afro-latin. Le groupe "Krudxs Cubensi" (ils ont changé le féminin "a» de leur nom d'origine en neutre " $x$ ") a fait de leur corps et de leur travail musical un champ d'expérimentation et un moyen d'expression des luttes qui avec le même objectif, se positionnent contre la politique cubaine et son gouvernement aussi bien que contre les macro-puissances qui essaient de nous contrôler au niveau mondial.

\section{ÍNDICE}

Mots-clés: Krudxs Cubensi, glolocal, lgbtiq, intersectionnalités, Cuba, rap, CENESEX.

Palabras claves: Krudxs Cubensi, glolocal, lgbtiq, interseccionalidades, Cuba, rap, CENESEX.

\section{AUTOR}

\section{MABEL CUESTA}

Estudios US Latino y Caribeños

Departamento de Estudios Hispánicos

University of Houston

mcuesta@uh.edu 